\title{
USE OF EXTERNALLY-POWERED ORTHOSIS TO ADDRESS COMPLEXITIES ASSOCIATED WITH BILATERAL BRACHIAL PLEXOPATHY
}

\author{
Cassandra Delgado, Debra Latour, \\ Handspring Clinical Services, Middletown, NY, USA. \\ Email: cassandra@poaprosthetics.com
}

DOI: https://doi.org/10.33137/cpoj.v1i2.32047

\section{INTRODUCTION}

Brachial plexus injuries are often caused by trauma, tumors or inflammation. The severity of the injury may vary, however in most traumatic cases, the supraclavicular region is impacted. Depending on the severity of the injury, surgery is often indicated early due to the likelihood of nerve regeneration. Surgical procedures include neurolysis, nerve grafting and neurotisation; where approximately $45 \%$ will regain adequate function to perform activities of daily living (ADLs) and return to work. According to current data, approximately 9,700 individuals per year will remain disabled due to the injury.

For individuals where surgical intervention has not provided improvement in function, alternative solutions must be investigated. Particularly for those with bilateral involvement, potential solutions include orthotic technology. Like users of prosthetic technology, there is a wide array of technology available, intended to meet the diverse needs experienced by the population of individual who have lost function of the upper limbs.

This paper describes the challenges experienced by an individual with bilateral brachial plexus injuries and addresses the case solutions using collaborative interprofessional practice. ${ }^{1-4}$

\section{METHODS}

The subject of this reflective case study is a 45-year-old female who presents with bilateral brachial plexus injuries due to complications from a bilateral mastectomy. She experienced complete loss of function of both upper extremities when she awoke from the surgery. She was discharged from the hospital without return of bilateral upper limb function. After 2 years of PT and OT, she regained $\sim 80 \%$ function in her nondominate left arm, however she fatigues quickly. She has some wrist and elbow flexion/extension range of motion return in her right upper extremity, however her strength is minimal and fatigue is apparent. The subject was employed as a family physician and has not been able to return to work, as she cannot carry her tablet or other equipment, is not able to type to chart on patients, cannot hold a scalpel to perform office procedures, and is not able to raise her arms to perform assessments. evaluation. It appeared that the subject would be a candidate for an externally-powered device.

Measures: A full evaluation was completed by both an OT and orthotist. The Quick DASH was administered with an initial General Disability Index of 88.6. In addition, the subject completed the McGann Client Feedback form. The subject received initial training in the device that included application to functional skills, in particular, tasks that involve reaching, lifting, pushing and bringing the hand to the head, such as to self-feed or to groom hair.

\section{RESULTS}

Subsequent testing reveals continued functional improvement, orthosis satisfaction and decreased perceptions of disability. These factors appear to align with the client-centered goals to return to work in any capacity as a physician, continue to provide for her two daughters.

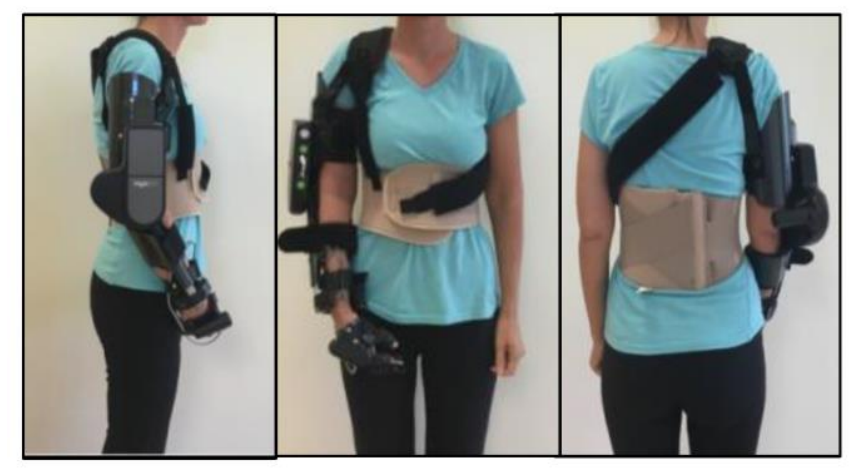

Figure 1: Externally-powered technology for individual with bilateral brachial plexus injury.

\section{DISCUSSION}

The externally-powered elbow-wrist-hand orthosis can provide significant benefit to the individual with bilateral involvement. The client with brachial plexus injury can 
perform functional tasks and engage in meaningful activities that other interventions cannot fully address.

\section{REFERENCES}

1. Michael, J.W, Nunley J.A. Special Considerations: Brachial Plexus Injuries: Surgical Advances and Orthotic/Prosthetic Management. Atlas of Limb Prosthetics: Surgical, Prosthetic, and Rehabilitation Principles; 12A, 2016. (http://www.oandplibrary.org/alp/chap12-01.asp).

2. Page S.J, Hill V, White S. Portable upper extremity robotics is as efficacious as upper extremity rehabilitative therapy: a randomized controlled pilot trial. Clinical rehab: 6,494-503, 2012. https://doi.org/10.1177/0269215512464795.

3. Sakellariou, et al. Treatment Options for Brachial Plexus Injuries. ISRN Orthopedics; 3,3, 2014. http://dx.doi.org/10.1155/2014/314137.

4. Mendal S, David B. A Myoelectrically Controlled WristHand Orthosis for Brachial Plexus Injury: A Case Study. J of Prost Ortho, 4,171-175, 1992.

\section{DISCLOSURE}

None. 